\title{
PHYSIOLOGICAL TREMOR
}

\author{
BY \\ JOHN MARSHALL AND E. GEOFFREY WALSH \\ From the Neurological Unit, Northern General Hospital, and Department of Physiology, University of Edinbur
}

Rhythmicity during muscular contration has long been studied. The earliest observations dealt with the sounds that can be heard on listening to a contracting muscle and were naturally limited by the poor sensitivity of the ear at low frequencies. When, in the second half of the nineteenth century, graphic recording techniques became readily available a number of papers were published dealing with the periodicity that can be recorded in myograms. Of outstanding interest were the findings of Schäfer (1886) who observed that

" The curve of a voluntary muscular contraction... invariably shows, both at the commencement of the contraction and during its continuance, a series of undulations which succeed one another with almost exact regularity, and can, as it would seem, only be interpreted to indicate the rhythm of the muscular response to the voluntary stimuli which provoke the contraction. . . . The undulations ... are plainly visible and are sufficiently regular in size and succession to leave no doubt in the mind of any person who has seen a graphic record of muscular tetanic contraction produced by exciting the nerve about 10 times in the second that the curve ... is that of a similar contraction."

Schäfer did not discuss the natural periodicity of his recording system and his results were regarded as artefacts by Haycraft (1890). Nevertheless, other authors using different apparatus obtained somewhat similar results. As Schäfer's observations, if valid, might be expected to throw light on the organization of voluntary movements, it seemed important to see whether his results could be verified using apparatus which would give a faithful record of movement. The observations to be reported confirmed in large measure the facts reported by Schäfer. It then became necessary to enquire as to the origin of the rhythmicity. Horsley and Schäfer (1886) had found that a similar $10 \mathrm{c}$./ $/ \mathrm{sec}$. rhythm was present in graphic records of the movements of monkeys following stimulation of the motor cortex, and descending motor pathways at various frequencies. They stated:

"We have found in nearly all cases that whatever the rate of excitation employed, provided it was allowed to fall below a certain limit, the frequency muscular response to stimulation of the cortex, indicated by the undulations described by the myograph lever, does not vary with the rate of excitatigh, but maintains a nearly uniform rate of about 10 per second."

They concluded that the rhythmicity was determined at a spinal rather than at a cortical level.

With the discovery of the alpha waves of the electro-encephalogram the view has sometimes been advanced that physiological tremor of muscles nis dependent upon impulses descending fromo the cerebral cortex at a rate of $10 \mathrm{c}$. $/ \mathrm{sec}$. Since Ho\&s\&y and Schäfer's observations appear directly oppsiset to this view we have attempted to determinetre neurological level responsible for physiologicil tremor.

\section{Methods}

Most of the observations reported in this paper been concerned with acceleration rather than displacement. The measurement of acceleration is advantagegus for three reasons. First, the application of Newtops second law indicates that the force put into a limb wal be reflected in its acceleration. Secondly, graphic records of acceleration reveal smaller discontinuities during the course of a movement than could be detected by conparable recording of displacement. Thirdly, the technique is simple and versatile.

An accelerometer double diode (Mullard DDR 10 was attached to a part of the limb under investigatiot The anodes of such a valve are deflected by acceleration in one plane. Movement of the valve upset the balarie of a bridge circuit, and the electrical output was fed through an Ediswan electro-encephalographic amplifier to both an ink-writer and an oscillograph.

The natural period of the accelerometer valve wias $1,000 \mathrm{c}$. $/ \mathrm{sec}$., and it may be regarded as accuratehy recording motion having sinusoidal components up to $250 \mathrm{c}$. $/ \mathrm{sec}$. (manufacturer's figures). The response of the ink-writer was more limited; signals higher in frequen than $90 \mathrm{c}$./sec. would be seriously attenuated.

In order to ensure that the ink-writers on which the bulk of the recordings were to be made were able satjs factorily to follow the movements which we were likely to encounter, over 100 oscilloscope recordings werle 
photographed and studied. These comprised a wide variety of normal and abnormal movements. We were satisfied, as a result of these observations, that the inkwriters gave faithful records. This claim requires qualification. Owing to the use of a condenser coupled electro-encephalographic amplifier very slow accelerations were not recorded. The time constants used were 0.3 and 1.0 second. Because of this a movement may sometimes be recorded as an acceleration in one direction without the complementary swing of the record to the other side of the baseline corresponding to the phase of deceleration. This peculiarity does not affect the recording of the more rapid fluctuations with which this study has been concerned. Finally, it should be noted that a device of this nature is inevitably sensitive to centrifugal force and to gravity. Accordingly, since rotation was not restricted, and was inevitable in some of the movements studied, the potential records do not represent solely linear acceleration. These complications do not interfere with the purposes of the study, but the calibration in terms of " $g$ " is meaningful only when the excursions are small, as in the maintenance of a posture.

The apparatus was calibrated by fixing the valve in a block of wood that fell in guides. An accelerometer falling freely produces a signal of constant amplitude but, because of the time constant of the amplifier, the record showed instead an exponentially decaying response. This was interrupted irregularly as the block of wood in falling ricocheted along the guides. In spite of this the determinations can be regarded as reliable for measurements of the distance travelled in a given time corresponded closely with the calculated values.

To dissect movement further, apparatus was used that was sensitive to the rate of acceleration, the fourth derivative of displacement. The transducer was a piezo-electric crystal, taken from a Brush headphone to which was cemented a small aluminium pellet to act as a mass. The input impedance of the attenuator with which the crystal was connected was $700,000 \mathrm{ohms}$ and the time constant of the combination was 0.03 sec., a value short compared with the periodicity of the movements that were investigated. The crystal was almost critically damped, and its natural period was $60 \mathrm{c} . / \mathrm{sec}$. Such a device is inevitably sensitive to twisting as well as to linear motion. The currents produced by the crystal were recorded with standard electro-encephalographic apparatus, using an ink-writing pen. The device and the recorder cannot be regarded as displaying the fourth differential of position with great precision, but it is believed that the inaccuracies that may have been introduced have not given rise to misleading interpretations. For calibration the transducer was attached to a pendulum. The amplitude of the deflections that were observed when the swing was a known amplitude, together with a knowledge of the periodicity of the device, allowed an appropriate calibration to be performed.

\section{Results}

Effect of Rate of Movement and Recording Site v. Frequency of Physiological Tremor in Normal Adults.-The type of record may be illustrated in

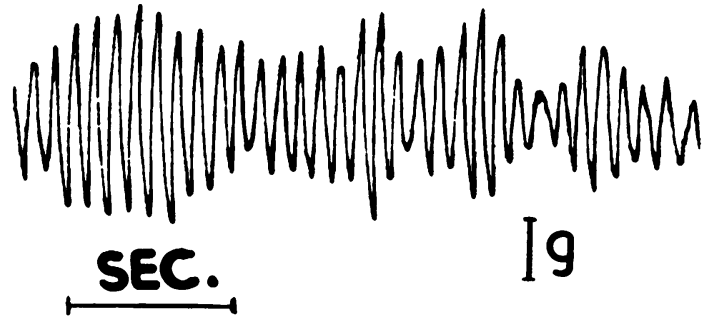

Fig. 1.-Tracing of wrist flexion and extension in a normal adult showing prominent $10 \mathrm{c} . / \mathrm{sec}$. rhythm.

the first instance by those obtained when the accelerometer valve is held in the hand, and the wrist alternately flexed and extended. Movements of this kind when performed rapidly produce swings of the tracing which may for part of their course be smooth in contour. It is frequently noted, however, that superimposed upon the large swings of the baseline there is a series of oscillations of about $10 \mathrm{c} . / \mathrm{sec}$. If a series of movements is made it is found that the prominence of the $10 \mathrm{c}$. $/ \mathrm{sec}$. rhythm increases, and the size of the baseline swing decreases the slower the movement. Eventually the movement breaks up into a series of discontinuities at 7 to $13 \mathrm{c} . / \mathrm{sec}$. (Fig. 1). The waves are quasisinusoidal. They constantly vary in shape, in duration, and in amplitude. No two movements will produce identical records. The size of the waves varies considerably in different people, and in the same person from time to time. A large change in the rate at which the movement is performed is liable to alter the amplitude but not the frequency of the waves. Faster components in the record may often be recognized by using high amplification and a fast $(6 \mathrm{~cm}$. $/ \mathrm{sec}$.) paper speed. These features have always been inconspicuous and we have paid little attention to them. At no time did a rhythmic discharge at $50 \mathrm{c}$. $/ \mathrm{sec}$. clearly manifest itself. Such a "Piper" rhythm might have been expected, for with powerful contractions the electromyogram gives evidence of synchronization at this frequency. Occasionally, however, short but well defined bursts of activity were recorded with a frequency of 15 to $20 \mathrm{c}$./sec.

On investigating the tremor in normal adults it was found that the frequency of the oscillations was much the same at a number of different sites. Thus activity at 7 to $12 \mathrm{c}$./sec. was seen at the wrist, elbow, shoulder, ankle, knee, and hip. Other workers also have recorded similar discontinuities in graphic records taken from a number of sites (Table I). Often the tremor may be found when the part of the body under investigation is merely resisting gravity, but sometimes it may be clearly recordable only during the course of a movement. 
TABLE I

FREQUENCY OF TREMOR AND LOCATION

\begin{tabular}{l|l|l}
\hline \multicolumn{1}{c|}{ Authors } & Recording Site & Frequency of Tremor \\
\cline { 1 - 2 } Schäfer (1886) & $\begin{array}{l}\text { Opponens pollicis } \\
\text { Biceps }\end{array}$ & $10 / \mathrm{sec}$. \\
Griffiths (1888) & $\begin{array}{l}\text { Thenar eminence } \\
\text { Biceps }\end{array}$ & $10-15 \mathrm{sec} / \mathrm{sec}$. \\
Harris (1894) & Tongue & $14 / 18 / \mathrm{sec}$. \\
& Neck muscles & $10-15 / \mathrm{sec}$. \\
Ditchburn and Ginsborg & Thenar eminence & $12 / \mathrm{sec}$. \\
(1953) & Eye & $30-80 / \mathrm{sec}$. \\
Eliasson and Gisselsson & Tensor tympani & $10-20 / \mathrm{sec}$. \\
(1955) & & \\
\hline
\end{tabular}

The waves were on a number of occasions noted to be of greater amplitude when the limb was being lowered than when it was being raised at about the same rate. To check this point further a small weight was caused to oscillate up and down in a sinusoidal fashion, being carried on a string attached to a motor-driven pulley. The person followed the weight with his upper limb, keeping his finger level with the weight. Some control, therefore, was possible over the rate at which the arm was raised and lowered. It was possible to find a velocity at which tremor waves were seen readily on the curve corresponding to the descent whilst the ascent was smooth (Fig. 2). It may be remembered that when a limb is lowered active units are being stretched, a condition in which the twitch tension is increased (Hill, 1949).

Effect of Load upon the Tremor.-The effect of loading the limb was investigated. If a weight was placed upon the hand during movement of the wrist the rhythm often became less in amplitude, but again changed little in frequency. On the other hand, with the shoulder the application of weight often made the tremor waves more prominent; again, however, they did not appear to alter in frequency (Fig. 3).

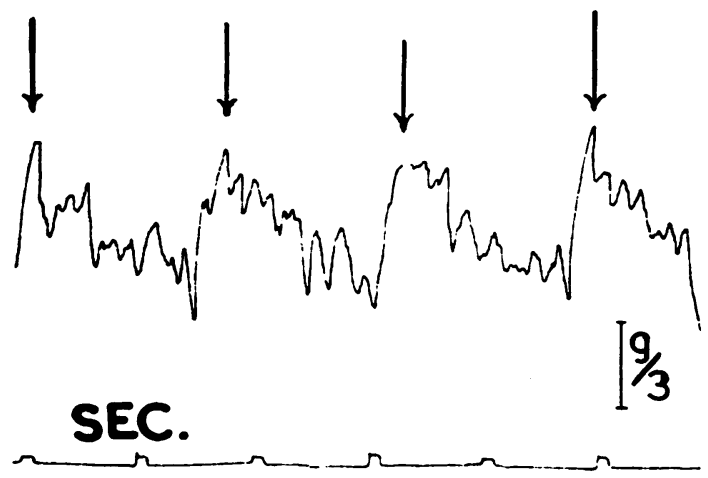

FIG. 2.- Record of hand following a weight moving up and down in a sinusoidal fashion, the top of the excursion being marked by an arrow. Ascent is smooth; descent shows slow tremor waves.

\section{SHOULDER UNWEIGHTED}

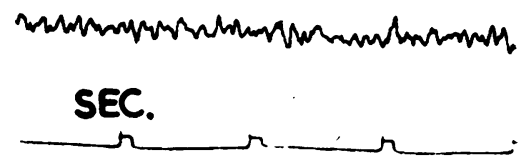

SHOULDER WEIGHTED

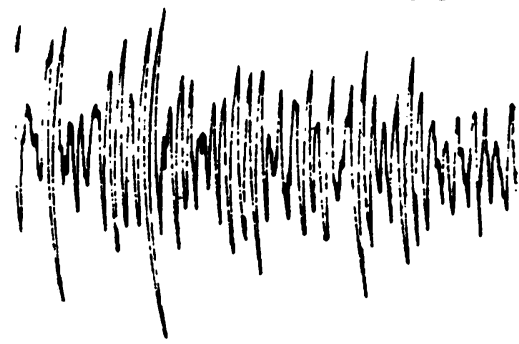

SEC.

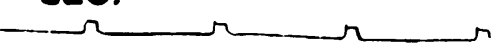

Fig. 3.-Record illustrating the effect of adding $4 \cdot 3 \mathrm{~kg}$. weight to upper arm during abduction.

As with the data discussed above we found, a fter having recorded these facts, that similar observetions had been reported many years ago (Griffilhs, 1888; Herringham, 1890). Intense voluntary e o may, however, make the waves increase in frequencis. Thus when the extensors of the wrist are thrown into play with maximum force the waves recordeg from the dorsiflexed hand were consistently foured to increase in rate by a few cycles per second.

Characteristics of Physiological Tremor in Normat Children.-Six normal children, aged from 18 months to 9 years, were investigated. It immediately becange apparent that the tremor, in all except the oldest, was slower than in the adults (Fig. 4). Slow rates of tremor were found both during movements and when the limbs were merely supporting their ove weight. Slow tremor was found at the wrist, elbow shoulder, ankle, and knee. At the hip the frequener was somewhat higher (Table II). When the limfo was called upon to support an additional weigh? except in one instance (F. J. W.), no consistegुt alteration in the frequency of the oscillations was observed, although in some of the records the dis turbances were rather variable in frequency an small changes of a statistical nature would not appreciated merely by examining the records visuall Young children are often notoriously clumsy performing fine movements (cf. Montessori methods) and this slow frequency tremor must surely contribute 


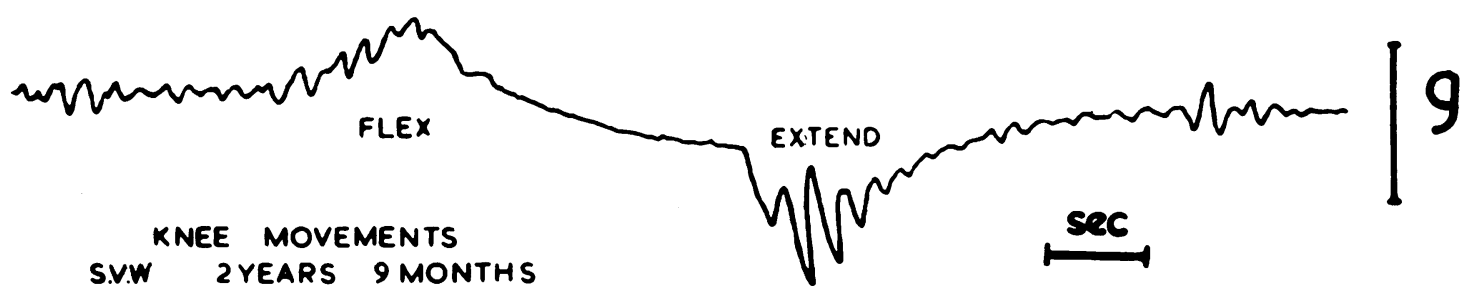

FIG. 4.-Physiological tremor during knee movements in a child.

TABLE II

FREQUENCY OF PHYSIOLOGICAL TREMOR IN CHILDREN

\begin{tabular}{|c|c|c|c|c|c|c|c|}
\hline Child & $\left|\begin{array}{c}\text { Age } \\
\text { (years) }\end{array}\right|$ & Wrist & Elbow & Shoulder & Ankle & Knee & Hip \\
\hline $\begin{array}{l}\text { P.M. } \\
\text { S.v.W. } \\
\text { J.P.W. }\end{array}$ & $\begin{array}{l}1 \frac{1}{2} \\
2 \frac{8}{4} \\
5\end{array}$ & $\begin{array}{c}\overline{3-5} \\
4 \frac{1}{2}-5 \frac{1}{2} \\
(3)^{*}\end{array}$ & $\overline{\overline{4}}$ & $\begin{array}{l}4-5(4-5) \\
4-5(3-6)\end{array}$ & $\begin{array}{c}\overline{3 \frac{1}{2}} \\
5(4)\end{array}$ & $\begin{array}{c}5 \\
3 \\
4\left(3-4 \frac{1}{2}\right)\end{array}$ & $\frac{\overline{8}}{2 \text { and } 9}$ \\
\hline F.J.W. & 5 & 6 & $3 \frac{1}{2}(7)$ & $31(5)$ & $5\left(3 \frac{1}{2}\right)$ & $3 \frac{1}{2}-4(4)$ & $\begin{array}{l}1 \frac{1}{2} \text { and } 8 \frac{1}{2} \\
\text { (two } \\
\text { rhythms) }\end{array}$ \\
\hline M.M. & $7 \frac{1}{2}$ & $\begin{array}{l}5-7 \frac{1}{2} \\
(4)\end{array}$ & - & $4(5)$ & - & - & - \\
\hline A.S. & $9\}$ & $6-10$ & 4-11(8) & $5-7(5)$ & - & - & - \\
\hline
\end{tabular}

*Figures in brackets refer to tremor frequency with extra weight applied.

to this ineptitude. No previous investigations of physiological tremor in children have been traced.

Relationship to Electro-encephalogram.-Most of the observations recorded so far could be interpreted as the result of a central clocking mechanism facilitating the discharge of the motor neurons once every cycle (one-tenth of a second in the adult). There have been reported a number of observations that have been considered to favour the view that the excitability of the anterior horn cells fluctuates in time with the electro-encephalogram. That the tremor is slower in children might be regarded as in favour of this view for the waves of their electroencephalogram also are of lower frequency. This hypothesis was tested in two ways.

Measurements were made of the moment at which a voluntary act was performed whilst the electro-encephalogram was recorded. Two subjects with a prominent alpha rhythm were chosen. It was found that the movements occurred at all phases of the alpha waves. Two experiments of this type are insufficient evidence on which to reject the hypothesis but an extended series of observations made elsewhere have yielded similar results (Crossland, personal communication).

The second approach was to show that muscular action tended to occur in jerks every $1 / 10 \mathrm{sec}$. after exclusion of the forebrain. Observations were made on two patients with complete division of the spinal cord. The accelerometer was attached to the foot and a flexor withdrawal reflex was elicited by stimulation of the sole of the foot with a pin, or by means of an electric current. The recordings that were obtained clearly showed the existence of a $10 \mathrm{c}$./sec. rhythm (Fig. 5).

Possible Synchronization of Motor Neurons.-A second hypothesis is that the rhythmicity is the result of synchronous discharge of different motor neurons. This problem is not readily solved by electrical recording from the interior of the muscle because it is so often uncertain, on recording synchronous discharges from different regions, whether the electrodes are recording from the same or from different motor units. Certain lines of evidence suggest that synchronization is not important for normal tremor:-

(1) Electromyography using surface leads gives no evidence of synchronization. Simultaneous mechanical and electrical recordings show the $10 \mathrm{c}$. $/ \mathrm{sec}$. rhythm in the former but not in the latter (Fig. 6).

(2) The observations that have been made may be contrasted with conditions in which synchronization is established. Two forms of synchrony

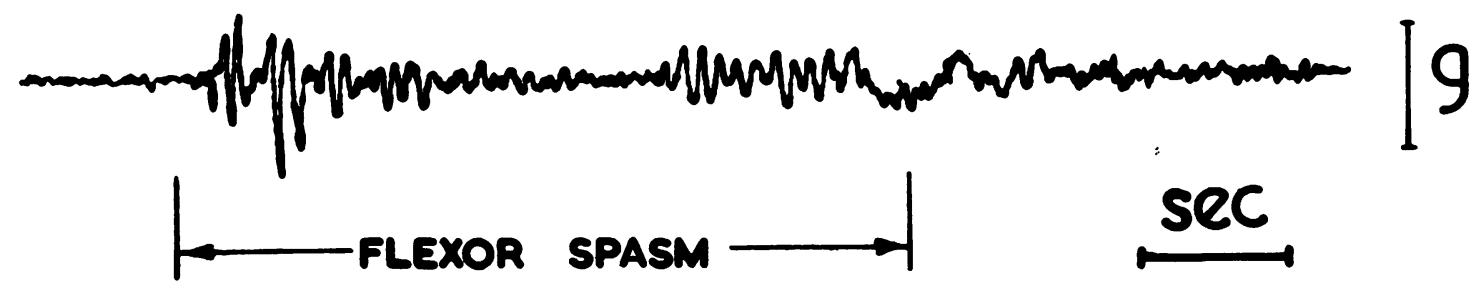

Fig. 5.-Tremor waves from foot during flexor spasm in an adult with complete transection of the spinal cord due to transverse myelitis. 


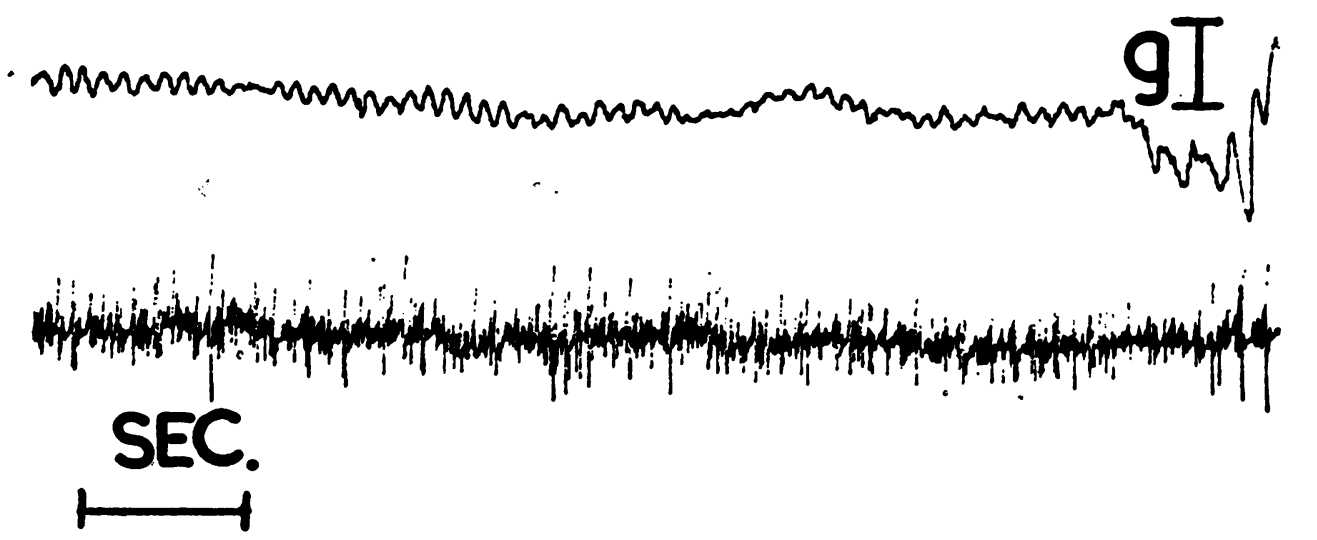

FIG. 6.-Simultaneous records of acceleration at wrist (upper trace) and electrical activity of wrist extensors recorded with surface lead (lower trace), show no evidence of synchronization in the electromyogram.

are known to occur in motor nerves: (a) A discharge of many elements at the same moment. This is found in clonus (Fig. 7). (b) A discharge of elements at different moments but with similar periods of activity and of quiescence, so that they fire in turn at different phases of the rhythmic movements. This type of synchrony is presumed to occur in Parkinsonism. In records of the acceleration of limbs with Parkinsonian tremor a $5 \mathrm{c}$. $/ \mathrm{sec}$. and a $10 \mathrm{c}$. $/ \mathrm{sec}$. tremor have sometimes been superimposed. This finding has been recorded by others also (Horsley, 1885; Wolfenden and Williams, 1888; Herringham, 1890).

The arguments against synchronization would gain force if it could be shown that the contraction of a single motor unit caused effects of an amplitude comparable to those of the tremor. It seemed logical therefore to study fasciculation. Accordingly, a series of five subjects was investigated who had, at some time in the past, suffered from poliomyelitis. Fasciculation is common long after an acute attack of this disease. We were struck by the observation that some unexpected movements weege experienced by all but one of these patients. OP electronic technician with wasting of the left forearm noticed that when he soldered with his right hand his left thumb "waltzed". A general practitionêf with wasting of the left deltoid noted that ofien when using his right hand to place his stethoscopes on the chest of a patient his left deltoid contracted $\frac{\mathrm{l}}{\mathrm{l}} \mathrm{a}$ series of jerks. During the course of an investigation one of the subjects (Miss M, aged 20) began to nofie slight involuntary movements of the ankle. Elegresmyographic recording over the lower end of calf revealed discharges of simple form (Fige 8 . When allowance is made for the undulations of baseline the discharges are clearly of the " all of none" pattern. The discharge was followed overa period of 400 seconds. Although the frequency Qf the impulses varied their size was uniform. The was thus nothing to indicate that the discharge wods due to a synchronization of motor units. Thos evidence, that the discharge of a single motor nerge fibre may give rise to small but detectable mechanical

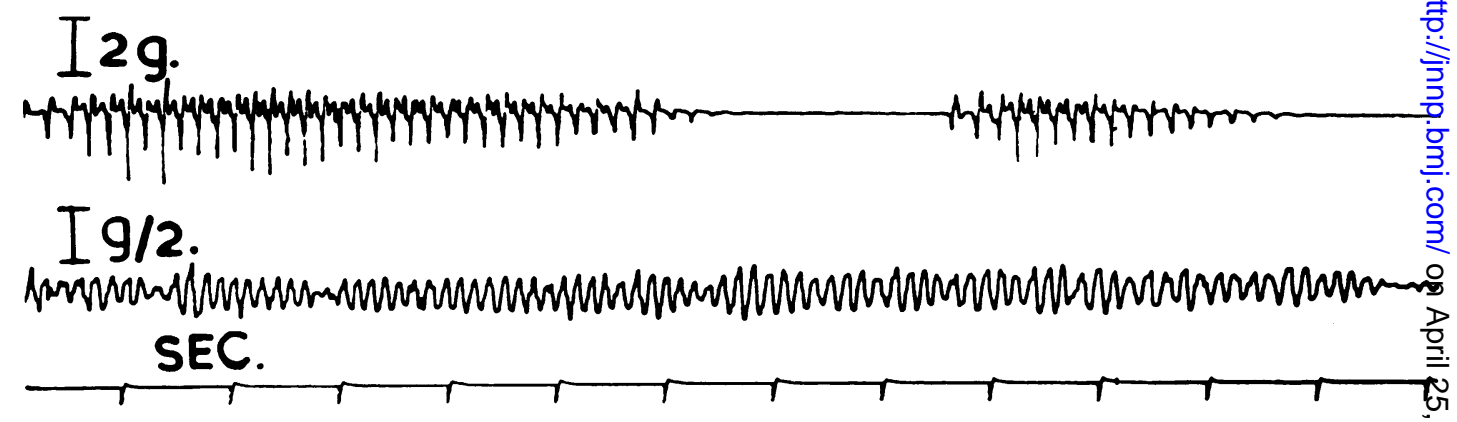

Fig. 7.-Record of rate of change of acceleration during two bursts of clonus from hemiplegic calf (upper trace) and during voluntaf movement of normal calf (lower trace). 


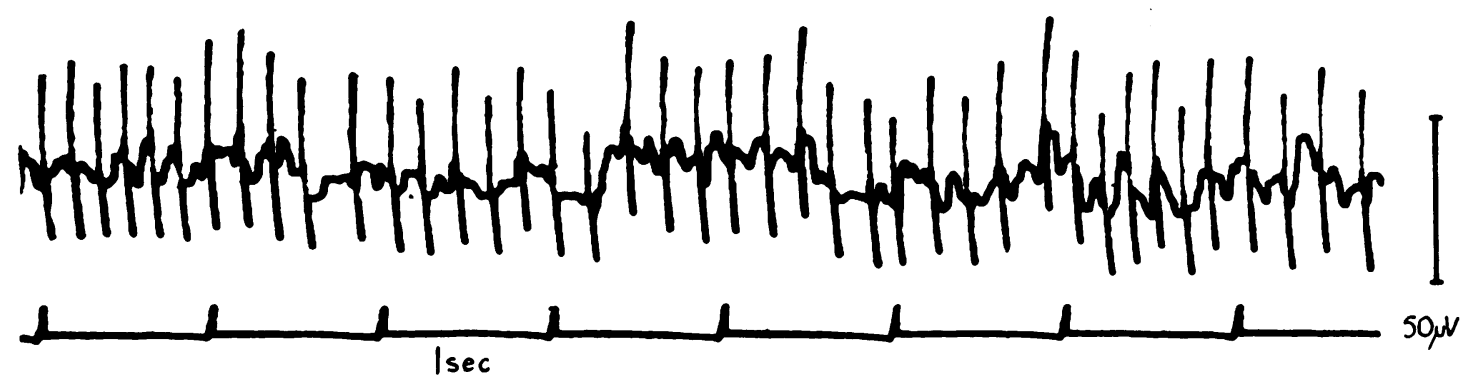

FIG. 8.-Single unit discharges recorded with surface leads during fasciculation in an adult with old poliomyelitis.

effects, loses some strength for it is possible that the units that survive in poliomyelitis are larger than normal. On the other hand, the effects of this unit were clearly greater than many of the waves of a physiological tremor.

If it is true that the discharge of a single motor nerve fibre could account for physiological tremor, it might be expected that the disturbances would be found as readily when few fibres were active as when many were coming into play. To obtain additional information on this point electromyography was performed using surface leads at a number of points on the musculature involved in the movements. To emphasize the discontinuities of the movement records were simultaneously made of the velocity of the acceleration. It was found that strikingly abrupt alterations were recorded from the mechanical transducer during the beginning of the movement, but these largely ceased during sustained contraction when many units had been recruited. On relaxation even more striking effects were seen at a time at which many units had dropped out of action. It sometimes happened that the most striking mechanical events occurred just after the electromyographic tracing had become quiescent. These findings are compatible with the production of the discontinuities by a single unit, or at most by a few units.

The Muscle as a Low Pass Filter.-During a steady voluntary contraction motor units start discharging at about $7 \mathrm{c} . / \mathrm{sec}$. (Adrian and Bronk, 1929) and thereafter increase up to about $50 \mathrm{c}$./sec. We wondered whether the relative constancy of the frequency of the tremor waves was due to the action of the muscle. If tetanic fusion of twitches began at about $10 \mathrm{c} . / \mathrm{sec}$. the nervous discharges would become progressively less well converted into mechanical changes at the higher frequencies. Measurements were therefore made of the excursions of various parts of the body when rhythmic electrical stimuli were applied to muscles.

Brief, exponentially decaying shocks were delivered to a number of skeletal muscles, the stimuli boing applied to the motor nerve, or over the motor point. The movements were recorded by strapping the accelerometer over the bally of the muscle, or by registering the acceleration of the whole limb. A typical set of records is shown in Fig. 9. Very often there was a tendency for a resonance to ozcur at about $5 \mathrm{c}$. $/ \mathrm{sec}$. Whilst this appeared to bemechanical, reflex effects were not definitely excluded. On raising the frequency to $10 \mathrm{c}$./sec., or a little beyond, there was a great decrease in the mechanical result. Various muscles behaved rather similarly (biceps, extensors of wrist, flexors of wrist, gastrocnemius, and the various components of quadriceps).

If the rhythmicity observed in mechanical records was due to the influence just mentioned it should be possible to modify the amplitude of the tremor by altering the behaviour of the muscle itself. Thus, if the muscle processes were slowed so as more readily to form a tetanus, the size of the waves should be reduced. We therefore arranged to cool the forearm in a bath of crushed ice and investigated the responses whilst the wrist was held steady and when it was flexed and extended. The most striking feature of the records was a reduction in the amplitude of the tremor waves. This was seen in each of the six experiments. Moreover, there appeared also to be a reduction in frequency.
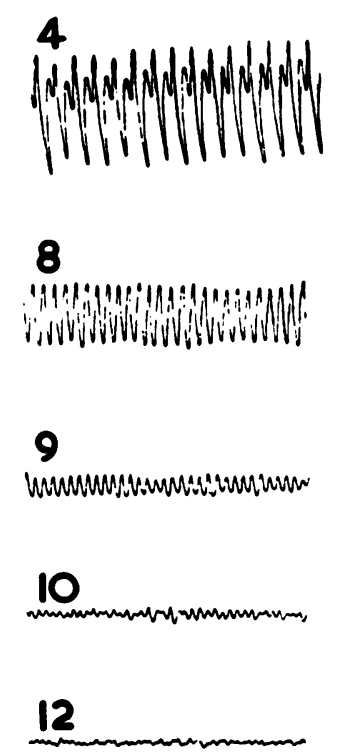

SEC.

FIG. 9.-Accelerometer recording from wrist flexors during stimulation of motor point at the frequencies indicated by the figures. 


\section{Discussion}

The Limb as a Pendulum.-Mechanical factors must be considered when discussing any form of tremor. Is it possible that the $10 \mathrm{c}$./sec. waves were due to the limb acting as a pendulum? Pendular knee jerks may illustrate this possibility. The limb is set moving by a brief contraction of the quadriceps, but the oscillations that follow are determined by the moment of inertia of the leg and foot. In such pendular action it is necessary to consider also any elastic elements operating across the swinging joint. The elasticity of muscles must be an important factor in determining the natural period of the arm when it is abducted. If the muscle is contracting powerfully the natural period will tend to be high; if it is relatively lax the natural period will be low. In moving a limb or part of a limb it is necessary to consider an instability that arises in terms not of neural or mechanical factors but in terms of the interaction of such effects.

In considering neural and mechanical interactions we may think of an oscillator (neural element) exciting a tuned circuit (mechanical element). Greatest effects will be expected when the oscillator operates at the same frequency as the tuned circuit. In a rapidly executed movement the tension of the muscles will be varying through a wide range continuously throughout the course of the movement. With such a brief contraction, therefore, the tuning of the limb segment will be constantly changing and no particular frequency will be emphasized. If the ripples of physiological tremor were due to a pendular-like action they should vary in duration according to the phase of the motion. No such systematic fluctuation has been observed. With longer lasting movements the tension exerted by the muscle can be fairly uniform over a significant period of time (isotonic contraction) and during this period the natural period of the segment will be relatively constant. Ripples of moderately constant repetition frequency may, therefore, be expected in the mechanical record. One conclusion would immediately follow: the more slowly a given movement was completed the lower the frequency of the irregularities. As the duration of a movement can be adjusted over a wide range there should be no difficulty in detecting this effect. It was not observed.

Feedback in the Stretch Reflex.-The possibility was considered that the tremor might be the result of feedback round the stretch reflex, but the evidence did nothing to support this possibility. The relevant facts may be summarized:-

(1) The similarity in the frequency of the tremor recorded from regions having short pathways to the cord with that of the waves from the dista parts of the extremities.

(2) The increase in the frequency of the waves during growth whilst the $\mathrm{H}$ reflex latency doubless between age of 6 and adult life (Wagman, 1954). To

(3) The evidence that physiological tremor my be found after division of the posterior roots (Altenburger in Bumke and Foerster, 1937, Fig. 16 p. 957, Vol. III; Lashley, 1917).

(We hoped to obtain useful information $\overrightarrow{\mathrm{n}_{\mathrm{y}}}$ studying tabes but our two sets of observatios were confusing; in one patient a $5 \mathrm{c}$./sec. trem was prominent, in another no definite tremor w⿳亠口⿵冂⿰㐅㐅木 recorded. This problem needs further investigation)

Relationship to the Alpha Rhythm.-The occutsrence of the $10 \mathrm{c}$. $/ \mathrm{sec}$. tremor in muscles innervated by a part of the spinal cord which was completely isolated from the forebrain excluded any possibility of its being determined by the alpha rhythm.

Possible Mechanism Underlying Physiologiç্⿸尸 Tremor.-The similarity of the frequency of physiological tremor at a number of sites indicates. it is suggested, not the existence of a central pocies maker, but similarities in the behaviour of diffexeif motor neurons of the striated musculature $\bar{P}$ ith which they are connected. It is necessary to reconcile two findings: (1) the tremor frequency does vary either with the velocity of the movement or with the load; (2) the discharge frequency of dividual motor units is known to increase increased effort (Adrian and Bronk, 1929).

We believe that two facts are relevant to $\vec{r}$ explanation of this apparent paradox: (1) Musçe stimulated more frequently than 15 times a second does not impart corresponding mechanical shocks of significant amplitude to the limb. (2) Motor neurons when first recruited in a steady voluntafy effort discharge at about $7 \mathrm{c}$./sec.

Adrian and Bronk (1929) believed that durin steady effort the motor neurons discharged asy chronously. Direct proof of this is difficult to obtain but no reason has been found for disagre ment with their conclusion. Physiological tremö. appears, therefore, to be an inevitable result of the being a finite number of motor nerve fibres. rate of discharge below about $15 \mathrm{c}$./sec. in the moto fibres is converted to mechanical ripples by the muscles, but higher rates of neural discharges a blocked or filtered by the physical constitution of the muscle. We failed to detect differences in the behaviour of different muscles when studying the limbs, although in animals having red and white. muscles differences are seen in response to repetitive stimuli. It is known, however, that the humang extra-ocular muscles have high tetanic fusiog 
frequencies. The rate of discharge of the corresponding motor neurons also is known to be higher than in the case of the limbs. These considerations seem to explain the exceedingly rapid tremor of the eyeball (Table I).

The regular tremor would not be seen if, when first recruited, the motor units started to operate at higher frequencies, but the result would be jerky for the full tetanic tension would be realized abruptly. On the other hand, too low a rate of initial discharge would result in an accentuation of the tremor. To obtain smooth control of movement it is clear that the behaviour of motor neurons must be rather closely matched to the properties of the muscle which they control. It is not known whether special mechanisms exist to secure this correlation throughout life.

\section{Summary}

Physiological tremor has been studied by the use of a valve sensitive to acceleration.

The tremor has been found to be similar in frequency (about $10 \mathrm{c}$./sec.) at a number of different sites.

Electromyography revealed no definite evidence of a synchronization of motor units at this frequency.

The relative constancy of the frequency appears to be due to a fusion of twitches at higher rates.

Lower rates of tremor are found in young children.

\section{REFERENCES}

Adrian, E. D., and Bronk, D. W. (1929). J. Physiol. (Lond.), $67,119$.

Bumke, O., and Foerster, O. (1937). Handbuch der Neurologie,

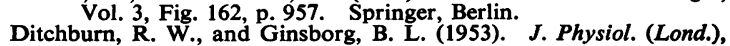
119, 1 .

Eliasson, S., and Gisselsson, L. (1955). Electroenceph. clin. Neurophysiol., 7, 399.

Griffiths, W. (1888). J. Physiol. (Lond.), 9, 39.

Harris, D. F. (1894). Ibid., 17, 315.

Haycraft, J. B. (1890). Ibid., 11, 352.

Herringham. W. P. (1890). Ibid., 11, 478.

Herlingham. A. V. (1949). Proc. roy. Soc. B., 136, 420.

Horsley, v. (1885). Brit. med. J., 1, i11.

, and Schäfer, E. A. (1886). J. Physiol. (Lond.), 7, 96.

Lashley, K. S. (1917). Amer. J. Physiol., 43, 169.

Schäfer, E. A. (1886), J. Physiol. (Lond.), 7, 111 .

Wolfenden, R. N., and Williams, D. (1888). Brit. med. J., 1, 1049. 